\title{
Proteinograma do leite de vacas lactantes submetidas à retenção láctea
}

Valéria Aparecida Caobianco SANT'ANA ${ }^{1}$ Eduardo Harry BIRGEL ${ }^{1}$ Andréa Maria Franco ROSENFELD

Pierre Castro SOARES 1

Correspondência para: VALÉRIA APARECIDA CAOBIANCO SANT'ANA

R. Judite França Costa, 183 - São Paulo/SP CEP 05592-040

valeria.santana@terra.com.br

Recebido para publicação: 24/05/2004 Aprovado para publicação: 13/07/2005

1 - Faculdade de Medicina Veterinária e Zootecnia da Universidade de São Paulo, São Paulo - SP

\section{Resumo}

Doenças, intensidade na criação e produção, bem como o manejo inadequado foram fatores considerados estressantes para vacas leiteiras, determinando a retenção de leite. Quatro vacas adultas, sadias e em plena lactação e sem antecedentes de mamites e/ou tratamento intramamário foram submetidas experimentalmente a $10 \%$ de retenção de leite, das quais colheram-se amostras de leite nos seguintes momentos (Tempos): antes da retenção, 12, 24, 36, 48, 60 horas durante a retenção e, 168 e 180 horas após o início do procedimento, ou seja, 108 e 120 horas após cessada a retenção. As amostras de leite foram, previamente, submetidas a exames físico-químico e microbiológico. O soro lácteo era obtido por coagulação do leite com renina e o proteinograma determinado por biureto e fracionamento por eletroforese em gel de poliacrilamida. Observou-se um gradativo e significativo aumento de algumas frações do soro lácteo: albumina e imunoglobulina sérica bovina; lactoferrina; $\alpha_{1}$-antitripsina; $\beta$ lactoglobulina e; $\alpha$-lactoalbumina. Ao final da experimentação os valores das frações protéicas, retornaram aos iniciais, momento anterior ao início da retenção láctea.

\section{Introdução}

A mamite dos bovinos, por ser uma doença multifatorial apresenta vários fatores predisponentes $^{1}$, entre os quais, devem ser destacados, em primeiro lugar, os relacionados ao meio ambiente: instalações, condições de higiene, ventilação e disposição dos bebedouros, bem como as práticas de manejo. A seguir, os fatores considerados inerentes às condições intrínsecas do animal, tanto as alterações anatomo-funcionais da glândula mamária e a ocorrência de enfermidades sistêmicas ou localizadas. Associam-se a esses fatores outros relacionados à magnitude da produção leiteira e ao manejo da ordenha, realçando-se ser a retenção láctea pós-ordenha na glândula um significativo fator predisponente a instalação e desenvolvimento de infecções causadoras de mamites, pois o leite retido na glândula não só atua como fator irritativo do tecido epitelial de revestimento interno da glândula, como também porque o leite retido representa um perfeito substrato para o desenvolvimento de microrganismos ${ }^{2}$.

A retenção láctea em vacas ocorre em conseqüência a fatores estressantes determinando pela liberação de adrenalina, que em sua atividade durante o processo da ordenha, impede a perfeita descida do leite e, conseqüentemente, determina a retenção láctea no úbere. McCaughan e Malecki ${ }^{3}$ demonstraram que vacas, em permanente estresse, retêem maior volume de leite na glândula mamária após a ordenha e, afirmaram que doenças como a rinotraqueíte infecciosa dos bovinos e a infestação de ectoparasitas seriam severos fatores estressantes e, assim sendo, determinantes do aumento da retenção láctea. Apesar disso, na revisão da literatura especializada poucas foram as pesquisas que avaliaram ou se propuseram demonstrar as alterações determinadas no leite, em decorrência da maior retenção láctea pós ordenha no úbere, 
especialmente, as variações de inúmeras proteínas lácteas, quer sejam as sintetizadas na própria glândula mamária, como também aquelas que surgiriam no leite, em decorrência de lesões do epitélio glandular. No entanto, alguns pesquisadores avaliaram a influência da redução do número de ordenhas sobre a composição química do leite de vacas ${ }^{4}$ e de cabras ${ }^{5}$. Assim esses pesquisadores complementaram o que fora estabelecido em 1981 por HonkanemBuzalski, Katila e Sandholm ${ }^{6}$ ao determinarem as alterações qualitativas das proteínas do leite em casos de inflamação da glândula mamária e por Östensson ${ }^{7}$ nas diferentes fases da lactação.

A técnica de eletroforese em gel de acrilamida foi utilizada por alguns pesquisadores para avaliar as alterações do quadro protéico no soro sanguíneo ${ }^{8,9}$ e no leite ${ }^{10,11}$ que consideraram essa técnica exeqüível e sensível para a detecção e mensuração das proteínas, em pequenas concentrações, nos fluidos orgânicos.

Apesar de existirem afirmações em compêndios, que a retenção láctea pósordenha seria uma das alterações da fisiologia da glândula mamária considerada predisponente às mamites, ${ }^{12,13,14,15,16}$ as variações do proteinograma do soro lácteo de bovinos e do possível significado da retenção láctea pós-ordenha como fator etiológico predisponente à instalação das mamites, não têm sido objeto de estudos. Assim sendo, objetivou-se na presente pesquisa avaliar a constituição protéica do soro lácteo de vacas lactantes submetidas à indução experimental de $10 \%$ de retenção do leite no úbere após a ordenha.

\section{Materiais e Métodos}

Foram utilizadas quatro vacas leiteiras, clinicamente sadias, adultas, em plena lactação, sem antecedentes de mamites ou de tratamento intramamários. A triagem desses animais foi realizada segundo recomendações de Grunert ${ }^{17}$ e Birgel $^{16}$, por exame físico do úbere, avaliação da celularidade do leite pelo CMT, determinação do pH, eletrocondutividade, teores de cloretos e exame microbiológico. As quatro vacas incluídas na pesquisa, não demonstraram variações significativas desses parâmetros e foram negativas no exame microbiológico.

No início da pesquisa realizou-se a avaliação do volume de leite obtido nas ordenhas da manhã e da tarde, usando-se o seguinte critério: cada quarto foi ordenhado até seu esgotamento completo, recolhendo o leite numa jarra graduada; após, aplicavase por via endovenosa 10 UI de ocitocina e, depois de 20 minutos, a vaca era novamente ordenhada, medindo-se assim o volume do leite residual. A partir da somatória dos volumes de leite obtidos nas duas ordenhas - plena e a do leite residual, calculava-se o volume de $10 \%$ do leite total ordenhado e que a seguir seria retido, segundo delineamento experimental. A colheita das amostras de leite, para determinação do proteinograma do soro lácteo de vacas com indução de retenção de $10 \%$ de leite, foi realizada durante uma semana, considerando a primeira colheita ou momento inicial, denominado tempo 1 (T1), constituindo o grupo controle. Os demais grupos foram assim formados: tempo 2 (T2) - amostras colhidas após 2 a 12 horas de retenção; tempo 3 (T3) amostras colhidas após 24 horas de retenção; tempo 4 (T4) - 36 horas após a retenção; tempo 5 (T5) - 48 horas após a retenção; tempo 6 (T6) - 60 horas após a retenção; tempo 7 (T7) - colheita da ordenha da manhã uma semana após a retenção, isto é, 168 horas após o início da retenção e 108 horas depois de cessar a retenção; tempo 8 (T8) - amostras colhidas uma semana (180 horas) após o início da pesquisa ou 120 horas após o fim do período de retenção de $10 \%$ de leite.

As colheitas das amostras de leite foram sempre realizadas antes da ordenha, sendo inicialmente, os tetos imersos em solução anti-séptica e secos, individualmente, com papel toalha, mas preliminarmente, era realizada a prova de exame do leite, em placa 
1 SIGMAMARKER-Low molecularweight range-Marca Sigma 2 Analisador Bioquímico Liasys com fundo escuro, segundo recomendações de Birgel ${ }^{2}$, observando-se a cor, consistência e presença de massas ou grumos do leite. Após a ordenha, os tetos eram novamente submetidos ao mesmo processo de antisepsia. As amostras de leite permaneciam acondicionadas em caixas de isopor com gelo e transportadas ao Laboratório onde foram submetidas aos exames de rotina, a saber: CMT, avaliação de $\mathrm{pH}$ e eletrocondutividade, determinação de cloretos e exame microbiológico ${ }^{17,16}$.

Esses exames que, inicialmente, serviram para triagens das vacas que seriam incluídas nesta pesquisa e durante o desenvolvimento do delineamento experimental monitorariam as possíveis alterações nos resultados dos exames físico-químico e microbiológico do leite, alertando para a necessidade de tratamento dos animais ou interrupção da pesquisa, por risco a saúde do animal.

Das amostras obteve-se o soro lácteo, coagulando-se o leite pela adição de 10\% de solução de renina, conforme descrito por Sant'Ana e Birgel ${ }^{18}$. O soro lácteo foi congelado à $-70^{\circ} \mathrm{C}$, até o momento da realização da eletroforese em gel de poliacrilamida.

O proteinograma do soro lácteo foi determinado por fracionamento e quantificação das proteínas, utilizando-se a técnica de eletroforese em gel de poliacrilamida, descrita por Fagliari, McClenahan e Evanson?. A identificação das proteínas foi determinada, comparando a curva do fracionamento à obtida com padrões elaborados com proteínas purificas. Utilizaram-se os seguintes padrões: blactoglobulina; a-lactoalbumina; $\mathrm{a}_{1}$ antitripsina; imunoglobulinas bovina e marcadores de peso molecular, variando entre 6.000 e 60.000 daltons $^{12}$. A concentração láctea de proteína total do soro lácteo foi determinada, utilizando-se analisador automático ${ }^{16}$, pela técnica do biureto, adaptada para determinação em amostras de fluídos orgânicos com pequena concentração protéica.

Os resultados dos vários parâmetros utilizados nesta pesquisa foram, inicialmente, submetidos ao teste de KolmogorovSmirnov, destinados à avaliação da distribuição normal de seus valores. A seguir, foi realizada análise de variância, adotandose o teste de Duncan para contraste entre as médias. Para completar a análise estatística dos resultados, realizou-se a análise de regressão, para verificar a relação entre pares de variáveis. A significância da regressão linear foi avaliada por meio do Teste F. Os valores dos resultados foram considerados significativos quando $\mathrm{p}<0,05^{19}$. Para análise estatística dos resultados utilizou-se programa computacional Statistical Analysis System ${ }^{20}$.

\section{Resultados}

Os resultados apresentados em duas tabelas e uma figura permitiram afirmar que, apesar de não haver variações significativas do teor protéico total do soro lácteo durante e após a retenção láctea de 10\% em vacas lactantes, elas foram observadas nas frações do proteinograma, tanto nas imunoglobulinas e albumina séricas; $\alpha_{1}$-antitripsina; como também na lactoferrina; $\beta$ lactoglobulina e; $\alpha$-lactoalbumina. Nas condições experimentais, os resultados foram significativamente maiores durante a retenção, para na fase final, após cessar a retenção láctea os valores determinados equivalerem-se àqueles iniciais.

$\mathrm{Na}$ tabela 1, cujos resultados foram configurados na figura 1 demonstrou-se, que as frações protéicas do soro lácteo estudadas aumentaram gradativa e significativamente durante o processo de retenção láctea, retornando aos valores iniciais ao final da avaliação. $\mathrm{Na}$ tabela 2 demonstraram-se correlações positivas e significativas $\mathrm{da}$ concentração da albumina sérica do soro lácteo com as concentrações de proteína total do soro lácteo, lactoferrina, fração de imunoglobulinas e antitripsina. Em contraposição, não se observou correlação dos valores obtidos para concentração de proteína total do leite e nem para a das proteínas de síntese na glândula mamária, isto 
Tabela 1-Valores médios e desvios-padrão das frações do proteinograma do soro lácteo de vacas submetidas a indução de retenção de 10\% do leite de ordenha, obtidos por eletroforese em gel de poliacrilamida. Resultados expressos em mg/dl, em amostras colhidas em 8 momentos do processo de retenção láctea. São Paulo - 2.004

\begin{tabular}{|c|c|c|c|c|c|c|c|c|}
\hline \multirow[b]{2}{*}{$\begin{array}{l}\text { Frações } \\
\text { Protéicas }\end{array}$} & \multicolumn{8}{|c|}{ Momentos do Processo de Retenção Láctea (Tempos) } \\
\hline & 1 & 2 & 3 & 4 & 5 & 6 & 7 & 8 \\
\hline \multirow{2}{*}{$\begin{array}{c}\text { Proteína Láctea } \\
\text { Total }\end{array}$} & $3.589^{a}$ & $3.550^{\mathrm{a}}$ & $3.545^{\mathrm{a}}$ & $3.510^{\mathrm{a}}$ & $3.454^{\mathrm{a}}$ & $3.454^{\mathrm{a}}$ & $3.424^{\mathrm{a}}$ & $3.408^{\mathrm{a}}$ \\
\hline & $\pm 67,7$ & $\pm 35,2$ & \pm 64 & $\pm 47,3$ & $\pm 62,2$ & $\pm 49,7$ & $\pm 73,2$ & $\pm 69,5$ \\
\hline \multirow{2}{*}{$\begin{array}{c}\text { Proteína Sérica } \\
\text { Total }\end{array}$} & $1.050^{\mathrm{c}}$ & $1.102^{\mathrm{bc}}$ & $1.219^{a b}$ & $1.256^{\mathrm{a}}$ & $1.249^{\mathrm{a}}$ & $1.253^{\mathrm{a}}$ & $1.088^{\mathrm{c}}$ & $1.088^{\mathrm{c}}$ \\
\hline & $\pm 33,4$ & $\pm 22,9$ & $\pm 15,8$ & $\pm 26,5$ & $\pm 25,8$ & $\pm 33,1$ & $\pm 43,9$ & $\pm 24,6$ \\
\hline \multirow{2}{*}{ Lactoferrina } & $64,2^{\mathrm{bc}}$ & $65,3^{\mathrm{bc}}$ & $85,2^{\mathrm{a}}$ & $90,5^{\mathrm{a}}$ & $76,1^{\mathrm{ab}}$ & $73,3^{\mathrm{ab}}$ & $52,0^{c}$ & $49,0^{c}$ \\
\hline & $\pm 5,3$ & $\pm 1,4$ & $\pm 3,6$ & $\pm 5,0$ & $\pm 4,3$ & $\pm 4,9$ & $\pm 4,2$ & $\pm 2,9$ \\
\hline \multirow{2}{*}{$\begin{array}{l}\text { Albumina } \\
\text { Sérica }\end{array}$} & $66,0^{c}$ & $72,2^{\mathrm{bc}}$ & $108,6^{\mathrm{a}}$ & $104,5^{\mathrm{a}}$ & $93,7^{a b}$ & $70,6^{c}$ & $80,7^{b c}$ & $78,2^{\mathrm{bc}}$ \\
\hline & $\pm 2,4$ & $\pm 4,9$ & $\pm 5,3$ & $\pm 5,4$ & $\pm 6,9$ & $\pm 4,8$ & $\pm 2,5$ & $\pm 5,6$ \\
\hline \multirow{2}{*}{$\begin{array}{c}\text { Fração de } \\
\text { Imunoglobulina }\end{array}$} & $68,5^{d}$ & $73,0^{c d}$ & $98,4^{\mathrm{ab}}$ & $92,8^{\mathrm{bc}}$ & $110,5^{\mathrm{a}}$ & $82,5^{\text {bcd }}$ & $85,6^{\text {bcd }}$ & $75,4^{\text {bcd }}$ \\
\hline & $\pm 3,4$ & $\pm 4,9$ & $\pm 5,7$ & $\pm 5,1$ & $\pm 5,0$ & $\pm 9,1$ & $\pm 4,0$ & $\pm 3,6$ \\
\hline \multirow{2}{*}{$\alpha_{1-\text {-antitripsina }}$} & $22,3^{c}$ & $28,8^{\mathrm{bc}}$ & $52,3^{a b}$ & $41,1^{\mathrm{bc}}$ & $68,1^{\text {a }}$ & $49,9^{\mathrm{ab}}$ & $38,8^{b c}$ & $19,7^{c}$ \\
\hline & $\pm 5,9$ & $\pm 5,8$ & $\pm 4,3$ & $\pm 3,8$ & $\pm 7,4$ & $\pm 5,8$ & $\pm 5,3$ & $\pm 4,1$ \\
\hline \multirow{2}{*}{$\begin{array}{c}\beta- \\
\text { Lactoglobulina }\end{array}$} & $357,3^{c}$ & $394,1^{a b c}$ & $470,3^{a b}$ & $452,1^{\mathrm{abc}}$ & $446,5^{\text {abc }}$ & $489,9^{a}$ & $390,7^{\mathrm{ab}}$ & $358,7^{c}$ \\
\hline & $\pm 33,5$ & $\pm 24,8$ & $\pm 19,4$ & $\pm 15,4$ & $\pm 17,2$ & $\pm 21,1$ & $\pm 27,7$ & $\pm 15,2$ \\
\hline$\alpha$ & $132,4^{b}$ & $141,8^{a b}$ & $171,9^{\mathrm{a}}$ & $148,9^{a b}$ & $151,5^{\mathrm{ab}}$ & $149,4^{\mathrm{ab}}$ & $119,8^{b}$ & $81,4^{\mathrm{c}}$ \\
\hline LactoAlbumina & $\pm 6,8$ & $\pm 6,9$ & $\pm 9,2$ & $\pm 4,9$ & $\pm 7,6$ & $\pm 12,6$ & $\pm 10,2$ & $\pm 7,8$ \\
\hline
\end{tabular}

Letras minúsculas diferentes na mesma linha indicam diferenças significativas entre os momentos (Tempos) de colheita $(\mathrm{p}<0,05)$

Tabela 2 - Coeficientes de correlação (r) entre as variáveis das frações do proteinograma do soro lácteo de vacas submetidas à indução de retenção de $10 \%$. Determinação por eletroforese em gel de poliacrilamida. São Paulo - 2004

\begin{tabular}{|c|c|c|c|c|c|c|c|c|}
\hline \multirow[t]{2}{*}{ Frações Protéicas } & \multicolumn{8}{|c|}{ Momentos do Processo de Retenção Láctea (Tempos) } \\
\hline & A & $\mathrm{B}$ & $\mathrm{C}$ & $\mathrm{D}$ & $E$ & $\mathrm{~F}$ & $\mathrm{G}$ & $\mathrm{H}$ \\
\hline $\begin{array}{l}\text { Proteína Láctea Total } \\
\text { (A) } \\
\text { Proteína Sérica Total } \\
\text { (B) }\end{array}$ & 1 & $0,06^{\mathrm{NS}}$ & $\begin{array}{r}-0,07^{\mathrm{NS}} \\
0,44^{* *}\end{array}$ & $\begin{array}{c}0,40^{*} \\
0,24^{* * *}\end{array}$ & $0,26^{* * *}$ & $0,27^{* * *}$ & $\begin{array}{c}-0,09^{N S} \\
0,65^{*}\end{array}$ & $\begin{array}{c}0,13^{\text {NS }} \\
0,52^{*}\end{array}$ \\
\hline Lactoferrina (C) & & & 1 & $0,36^{* *}$ & $0,30^{* *}$ & $0,09^{N S}$ & $0,37^{* *}$ & $0,27^{* * *}$ \\
\hline $\begin{array}{c}\text { Albumina Sérica (D) } \\
\text { Fração de }\end{array}$ & & & & 1 & $0,68^{*}$ & $0,28^{* * *}$ & $-0,02^{\mathrm{NS}}$ & $0,06^{\mathrm{NS}}$ \\
\hline Imunoglobulina (E) & & & & & 1 & $0,24^{* * *}$ & $-0,10^{\mathrm{NS}}$ & $0,10^{\mathrm{NS}}$ \\
\hline$\alpha_{1-\text {-antitripsina }(F)}$ & & & & & & 1 & $0,30^{* * *}$ & $0,54^{*}$ \\
\hline$\beta$-lactoglobulina (G) & & & & & & & 1 & $0,55^{*}$ \\
\hline a-lactoalbumina $(\mathrm{H})$ & & & & & & & & 1 \\
\hline
\end{tabular}

* $(\mathrm{P}<0,0001) ; *(\mathrm{P}<0,001) ; * *(\mathrm{P}<0,05)$; ${ }^{\text {NS }}$ - não significativo 
é, b-lactoglobulina e a-lactoalbumina.

\section{Discussão}

A eletroforese em gel de acrilamida demonstrou ser técnica adequada para avaliar quantitativamente as concentrações protéicas de fluídos orgânicos, quando as concentrações das frações fossem mínimas, como foi comprovado no soro sanguíneo por Hiller ${ }^{8}$ e Fagliari, McClenahan e Evanson $^{9}$ e no leite por Kato, Mori e Katoh ${ }^{10}$ e Urech e Puhan ${ }^{11}$, que além do mais destacam a sensibilidade da técnica. $\mathrm{Na}$ presente pesquisa comprovou-se que a técnica foi exeqüível, para determinação do proteinograma do soro lácteo, com sensibilidade suficiente para quantificar as frações protéicas oriundas da síntese do leite, bem como as transudadas do plasma sanguíneo para os tecidos e sistema excretor da glândula mamária. As seguintes frações protéicas foram determinadas de forma bem característica: proteína sérica total; albumina sérica; imunoglobulinas séricas; antitripsina sérica; lactoferrina, $\alpha$ lactoalbumina e $\beta$-lactoglobulina.

McCaughan e Malecki ${ }^{3}$ demonstraram resposta insuficiente da adrenocortical e retenção láctea em vacas produtoras de leite submetidas a estresse de ação persistente, porém, os pesquisadores não avaliaram as características dos constituintes físicoquímicos e microbiológicos do leite desses animais. As afirmações assemelhadas tornaram a retenção láctea em ruminantes lactantes um fato aceito e divulgado por inúmeros autores como condição etiológica predisponente às mamites, apesar de ter sido, especificamente, pouco estudado e avaliado $^{12,13,14,15,2,16}$

A análise dos resultados obtidos no soro lácteo de vacas submetidas a indução de $10 \%$ de retenção láctea demonstrou que, apesar de não haver variações nos teores lácteos total de proteína durante o desenrolar do processo, houve significativo aumento da concentração de proteína total do soro sanguíneo e de suas frações (albumina e imunoglobulinas) extravasadas para o leite, bem como de algumas proteínas de reação aguda, como ocorreu com a antitripsina e lactoferrina do soro sanguíneo.

A proteína total de origem sanguínea e suas frações-albumina e imunoglobulinas mostraram aumentos significativos entre 24 e 36 horas de retenção láctea, apresentando significativa correlação positiva e como não são sintetizadas na glândula mamária, os resultados sugeriram que elas se transferiram, por difusão, do sangue para o leite. Da mesma forma, demonstrou-se evidente aumento das concentrações de antitripsina e lactoferrina, oriundas do plasma sanguíneo nos mesmos períodos. Os resultados concordaram com aqueles apresentados por Honkanem-Buzalski, Katila e Sandhom ${ }^{6}$, que destacaram aumento da antitripsina e da albumina sérica bovina no leite de vacas acometidas por mamites. Assim ao afirmarse, baseado nos presentes resultados, que o aumento do conteúdo protéico de origem sanguínea no leite seria um indicador do aumento de permeabilidade do sistema vascular responsável pela circulação venosoarterial da glândula mamária, demonstrando ocorrência de fase incipiente de processo inflamatório de origem não inflamatória. Ressalte-se a concordância dessa afirmação com as manifestações feitas por HonkanemBuzalski, Katila e Sandhom ${ }^{6}$ permitindo a confirmação da hipótese que a retenção láctea pós-ordenha, na dependência de seu volume representa real fator etiológico predisponente às mamites no gado leiteiro, associando-se, freqüentemente, aos demais, considerados fundamentais para a disseminação da inflamação e infecção da glândula ${ }^{1}$. Os presentes resultados demonstraram, também, aumento significativo das concentrações da $\alpha$ lactoalbumina e da $\beta$-lactoglobulina após a retenção de $10 \%$ de leite. E, seus resultados apresentaram, também, relação significativa e positiva entre elas, bem como com a concentração de proteína total do soro lácteo. Resultados similares foram determinados por Kelly et al. ${ }^{4}$, que observaram aumentos 
da lactoalbumina e do número de células somáticas no leite de vacas submetidas à diminuição da freqüência das ordenhas no processo de secagem desses animais no período de repouso pré-parto. Todavia os citados pesquisadores, não observaram alterações significativas da concentração láctea de $\beta$-lactoglobulina, no mesmo período.

Ao observar-se na presente pesquisa que o teor de proteína total láctea não apresentou variações significativas durante a indução da retenção de 10\% de leite em

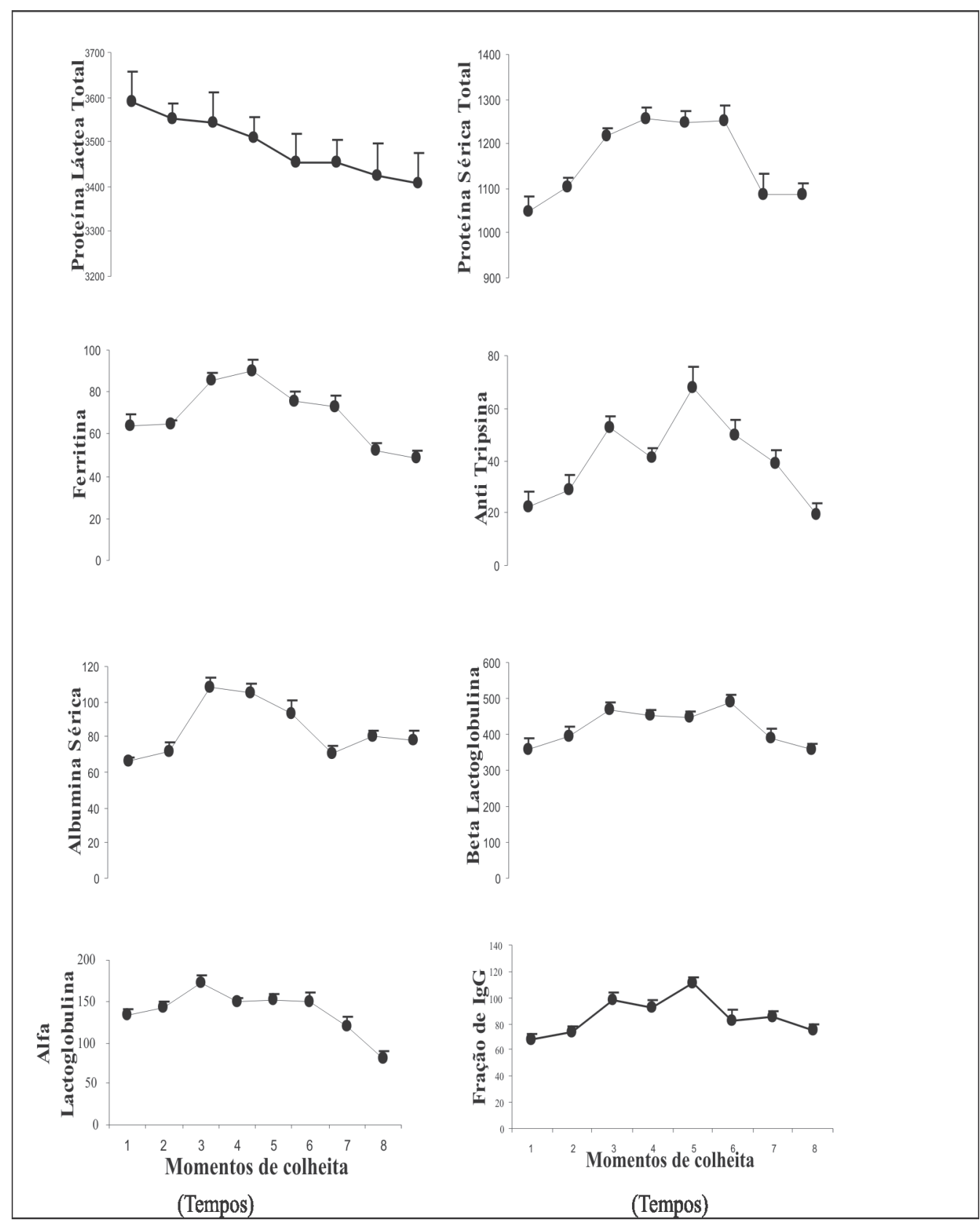

Figura 1 - Representação gráfica dos valores médios das frações do proteinograma do soro lácteo durantea indução da retenção de leite. Determinação por eletroforese em gel de poliacrilamida. Valores expressos em mg/dl - São Paulo- 2004 
vacas, discordou-se dos resultados determinados por Boutinaud et al. ${ }^{5}$ ao avaliarem o efeito da diminuição do número de ordenha sobre a constituição protéica do leite de cabras. Todavia a comparabilidade dos resultados, aparentemente paradoxal poderia ser atribuída ao fato do presente delineamento experimental determinar a obtenção do soro lácteo e, assim eles não incluíram os teores de caseína, cabendo apenas ressaltar que a retenção láctea aumentou o teor de proteínas sanguíneas que extravasaram do sistema vascular face ao aumento da permeabilidade dos vasos sanguíneos, conseqüente ao processo inflamatório não infeccioso da glândula mamária causado pela irritação do leite retido no úbere, entre as ordenhas.

Por apresentarem as frações protéicas do soro lácteo de vacas submetidas à indução de retenção de leite entre as ordenhas significativamente diferentes durante a evolução desse processo, para a utilização rotineira do proteinograma do soro lácteo há evidente indicação para fins de diagnóstico clínico das infecções da glândula mamária, sendo que a determinação do fracionamento eletroforético em gel de poliacrilamida substituiria com evidentes vantagens outras técnicas de avaliações protéicas no leite.

A análise dos resultados obtidos permitiu as seguintes conclusões:

1. O fracionamento eletroforético em gel de poliacrilamida é exeqüível para fracionamento protéico do soro do leite do gado leiteiro.

2. A retenção láctea de $10 \%$ determinou significativo aumento das frações protéicas não sintetizadas na glândula mamária durante período de retenção: albumina e imunoglobulinas séricas; lactoferrina e $\mathrm{a}_{1}-$ antitripsina, caracterizando processo inflamatório irritativo não infeccioso.

\section{Milk proteinogram of the cows submitted to milk retention}

\section{Abstract}

Diseases, breeding and production intensity, as well as inadequate handling were factors considered as stressful to milk cows, determining milk retention. Four healthy adult cows and in full milking period and without any prior mamits and/or intra-mammary treatment were experimentally submitted to $10 \%$ milk retention of which milk samples were collected at the following times: before milk retention, $12,24,36,48,60$ hours during retention and 168 and 180 hours after the initial procedure, or being, 108 and 120 hours after retention ceased. The milk samples were previously submitted to physic-chemical and microbiological exams. The whey was obtained by milk coagulation with renin and the proteinogram determined by biuret method and fractionizing by polyacrymalide gel electrophoresis. A gradual and significant increase of some fractions of the whey was observed: serum albumin and immunoglobulin bovine, lactoferrin; $\alpha_{1}$-antitrypsin; $\beta$-lactoglobulin and; $\alpha$-lactoalbumin. At the end of the experiment, the proteic fractions returned to their initial state, the moment previous to the initial milk retention.

\section{Referências}

1 TOLLE, A. Mastitis: The disease in relation to control methods. In: IDF SEMINAR ON MASTITIS CONTROL, 1975, Reading. Proceedings...Bruxelles: International Dairy Federation, 1975. p.3-15.
Key-words

Milk cow.

Retention of milk.

Whey proteins. diagnóstico da mamite bovina. In: BIRGEL, E. H. BENESI, F. J. Patologia clínica veterinária. São Paulo: Sociedade Paulista de Medicina Veterinária, 1982. p. 177-213.

3 MCCAUGHAN, C. J.; MALECKI, J. C. Milk retention in chronically stressed dairy cows. Australian Veterinary 
Journal, v. 57, n. 4, p. 203-204, 1981.

4 KELLY, A. L.; et al. Effect of decreased milking frequency of cows in late lactation on milk somatic cell count, polymorphonuclear leucocyte numbers, composition and proteolytic activity. Journal of Dairy Research, v. 65, n. 3, p. 365-373, 1998

5 BOUTINAUD, M.; et al. Growth hormone and milking frequency act differently on goat mammary gland in late lactation. Journal of Dairy Science, v. 86 n. 2, p. 509-520, 2003.

6 HONKANEM-BUZALSKI, T.; KATILA, T. SANDHOLM, M. Milk antitrypsin activity during clinical and experimental bovine mastitis. Acta Veterinary Scandinavian, v. 22, n. 1, p. 360-368, 1981.

7 ÖSTENSSON, K. Variations during lactation in total and differential leukocyte counts, N-acetyl-bglucosaminidase, antitrypsin and serum albumin in foremilk and residual milk from non-infected quarters in the bovine. Acta Veterinary Scandinavia, v. 34, n. 1 , p. 83-93, 1993.

8 HILLER, R. M. The quantitative measurement of whey proteins using polyacrylamide-gel electrophoresis. Journal of Dairy Research, v. 43, n. 2, p. 259-265, 1976 .

9 FAGLIARI, J. J.; MCCLENAHAN, D.; EVANSON, O A. Changes in plasma protein concentrations in ponies with experimentally induced alimentary laminitis. American Journal Veterinary Research, v. 59, n. 10, p. 1234-1237, 1998.

10 KATO, K.; MORI, K.; KATOH, N. Different protein patterns in normal and mastitic milks as revealed by sodium dodecyl sulfate-poliacrylamida del eletrophoresis. Japanese Journal Veterinary Science, v. 51, n. 6, p. 1275-1278, 1989.

11 URECH, E.; PUHAN, Z. Changes in milk protein fraction as affected by subclinical mastitis. Journal of Dairy Science, v. 82, n. 11, p. 2402-2411, 1999.

12 HEIDRICH, H. J.; RENK, W. Diseases of the mammary glands of domestic animals. Philadelphia: W.B. Sauders, 1967. 208 p.

13 SCHALM, O. W.; JASPER, D. E. Mastitis In: GIBBONS, W. J.; CATCOTT, E. J.; SMITHCORS, J. F. Bovine medicine and surgery, Illinois: American Veterinary Publications Inc., 1970. p. 711-740.

14 SCHALM, O. W.; CARROL, E. I.; JAIN, N. C. Bovine mastitis. Philadelphia: Lea\&Febiger, 1971. 360 p.

15 GRUNERT, E.; WEIGT, U. Enfermedades de la ubre. In: AHLERS, D. et al. Compendio de buiatria. 3 ed. Buenos Aires: Editorial Hemisferio Sur, 1979. p. 125170.

16 BIRGEL, E. H. Doenças da glândula mamária: mamite dos caprinos. Brasília/DF, ABEAS - (Curso de Especialização por Tutoria à Distância). 1999. 46 p.
17 GRUNERT, E. Weiblicher Geschlechtsapparat et al.: In: ROSENBERGER, G. Die klinische untersuchung des rindes. 3 aufl, Berlin, Verlag Paul Parey, 1990. p. 472-549.

18 SANT'ANA, V. A. C.; BIRGEL, E. H. Obtenção do soro lácteo para fracionamento das proteínas por eletroforese em gel de poliacrilamida. In: CONGRESSO LATINOAMERICANO DE BUIATRIA, 11 ; CONGRESSO BRASILEIRO DE BUIATRIA, 5 CONGRESSO NORDESTINO DE BUIATRIA, 3. Anais... Salvador: Associação Brasileira de Buiatria, 2003. p. 31.

19 SAMPAIO, I. B. M. Estatística aplicada à experimentação animal. Belo Horizonte: Fundação de Pesquisa e Ensino em Medicina Veterinária e Zootecnia, 1998. 221 p.

20 SAS INSTITUTE. SAS user's guide: statistics. Cary, SAS Institute, 1985. $956 \mathrm{p}$ 